\title{
Pengaruh CAR, NPL, NIM, BOPO Dan LDR Terhadap Profitabilitas Bank Umum Swasta Nasional Devisa
}

\author{
Yenni Vera Fibriyanti, Lilik Nurcholidah \\ Fakultas Ekonomi Universitas Islam Lamongan \\ Email corresponding author: yennivera@unisla.ac.id/ liliknurcholidah12@gmail.com
}

\begin{abstract}
ABSTRAK
Penelitian pengaruh CAR, NPL, NIM, BOPO dan LDR terhadap profitabilitas Bank Umum Swasta Nasional Devisa bertujuan untuk menganalisis pengaruh CAR, NPL, NIM, BOPO dan LDR secara parsial dan secara simultan terhadap profitabilitas Bank Umum Swasta Nasional Devisa. Data diolah menggunakan program IBM SPSS Statistics 20. Teknik pengambilan sampel menggunakan metode purposive sampling yaitu sampel dipilih berdasarkan kriteria tertentu. Berdasarkan uji t yang telah dilakukan dapat dibuktikan bahwa CAR $\left(\mathrm{X}_{1}\right)$ berpengaruh secara parsial terhadap profitabilitas $(\mathrm{Y})$. Hal ini dapat dilihat dari nilai sig. $b_{1}<5 \%(0,030<0,05)$. Variabel NPL $\left(X_{2}\right)$ tidak berpengaruh secara parsial terhadap profitabilitas $(Y)$ dengan nilai signifikan $b_{2}>5 \%(0,072>0,05)$. Variabel NIM $\left(X_{3}\right)$ berpengaruh secara parsial terhadap profitabilitas $(Y)$ dengan nilai signifikan $b_{3}<5 \%(0,003<0,05)$. Variabel BOPO $\left(\mathrm{X}_{4}\right)$ berpengaruh secara parsial terhadap profitabilitas $(\mathrm{Y})$ dengan nilai signifikan $\mathrm{b}_{4}<$ $5 \%(0,008<0,05)$. Variabel LDR $\left(X_{5}\right)$ tidak berpengaruh secara parsial terhadap profitabilitas $(Y)$ Bank Umum Swasta Nasional Devisa dengan nilai signifikan $b_{5}>5 \%(0,818>0,05)$. Berdasarkan hasil uji $\mathrm{F}$, dapat dilihat bahwa signifikansi $\mathrm{F}<5 \%(0,000<0,05)$, yang artinya secara simultan variabel CAR $\left(\mathrm{X}_{1}\right)$, NPL $\left(X_{2}\right)$, NIM $\left(X_{3}\right)$, BOPO $\left(X_{4}\right)$, LDR $\left(X_{5}\right)$ mempunyai pengaruh yang signifikan terhadap profitabilitas (Y) Bank Umum Swasta Nasional Devisa.
\end{abstract}

Kata Kunci: CAR, NPL, NIM, BOPO, LDR, profitabilitas dan Bank Umum Swasta Nasional Devisa

\section{PENDAHULUAN}

Dalam upaya mendukung adanya MEA dimana semua usaha mengalami ketergantuan perekonomian maka lembaga perbankan telah menunjukkan perkembangan yang sangat pesat, seiring dengan kemajuan pembangunan di Indonesia dan perkembangan perekonomian internasional agar kemajuan yang dialami oleh lembaga perbankan dapat ditingkatkan secara berkelanjutan dan benarbenar memberi manfaat bagi masyarakat, sehingga dapat ditumbuh kembangkan menjadi suatu kekuatan yang riil bagi peningkatan kemakmuran rakyat.

Sebagaimana kita ketahui saat ini peranan bank sangat dirasakan manfaatnya baik oleh masyarakat maupun pemerintah. Karena bank adalah badan usaha yang menghimpun dana dari masyarakat dalam bentuk simpanan dan menyalurkannya kepada masyarakat dalam bentuk kredit dan atau bentuk-bentuk lainnya dalam rangka meningkatkan taraf hidup rakyat banyak (Kasmir, 2009 : 25).

Semua fungsi-fungsi bank tersebut harus dikelola artinya bahwa semua fungsi tersebut harus berjalan pada saat yang bersamaan dan saling kait-mengkait untuk mencapai tujuan bank yaitu mencapai profitabilitas yang cukup dan 
mempertahankan kepercayaan masyarakat dengan menjaga posisi likuiditas tetap aman. Agar tujuan tersebut tercapai bank menerapkan manajemen pengelolaan bank. Pengelolaan bank tersebut diperlukan karena adanya perbedaan yang mendasar dalam karakteristik antara sumber dana dan penyaluran dana (Kuncoro, 2002:85).

Berdasarkan latar belakang di atas, maka penelitian ini bertujuan untuk menganalisis pengaruh CAR, NPL, NIM, BOPO dan LDR secara parsial terhadap profitabilitas dan untuk menganalisis pengaruh CAR, NPL, NIM, BOPO dan LDR secara simultan terhadap profitabilitas Bank Umum Swasta Nasional Devisa.

\section{TINJAUAN PUSTAKA}

\section{Bank Umum Swasta Nasional Devisa}

Taswan (2010:6) menyatakan bahwa bank adalah sebuah lembaga atau perusahaan yang aktivitasnya menghimpun dana berupa giro, deposito tabungan dan simpana yang lain dari pihak yang kelebihan dana kemudian menempatkannya kembali kepada masyarakat yang membutuhkan dana melalui penjualan jasa keuangan yang pada gilirannya dapat meningkatkan kesejahteraan rakyat banyak. Menurut Kasmir (2011:11) Bank adalah lembaga keuangan yang kegiatan utamanya adalah menghimpun dana dari masyarakat dan menyalurkannya kembali dana tersebut kepada masyarakat serta memberikan jasa-jasa bank lainnya. Jadi, dapat disimpulkan bahwa usaha perbankan meliputi tiga kegiatan, yaitu: menghimpun dana, menyalurkan dana, memberikan jasa bank lainnya.

Bank Umum Swasta Nasional (BUSN) adalah bank yang berbadan hukum Indonesia yang sebagian atau seluruh modalnya dimiliki oleh warga Negara Indonesia dan atau badan hukum Indonesia (Hasibuan, 2006).

Dilihat dari lingkup usahanya BUSN ada dua, yaitu : (a) Bank devisa (foreign exchange bank) dan (b) Bank Non-Devisa (nonforeign exchange bank). Bank devisa (foreign exchange bank) adalah bank yang dalam kegiatan usahanya dapat melakukan transaksi dalam valuta asing, antara lain menerima simpanan dan memberikan kredit dalam valuta asing termasuk jasa-jasa keuangan yang terkait dengan valuta asing, misalnya letter of credit, travelers check. ( Hasibuan, 2006).

\section{Rasio Keuangan}

Rasio CAR menunjukkan kecukupan modal yang dimiliki oleh suatu bank untuk mengatasi resiko saat ini dan mengantisipasi resiko di masa depan (Cecaria, 2015). CAR merupakan rasio permodalan yang menunjukkan kemampuan bank dalam menyediakan dana untuk keperluan pengembangan usaha dan menampung risiko kerugian dana yang diakibatkan oleh kegiatan operasi bank.

Non Performing Loan (NPL) menunjukkan bahwa kemampuan manajemen bank dalam mengelola kredit bermasalah yang diberikan oleh bank. Kredit bermasalah 
adalah kredit dengan kualitas kurang lancar, diragukan dan macet (Kurniasari, 2013). Semakin tinggi NPL, maka akan semakin buruk kualitas kredit bank.

Net Interest Margin (NIM) merupakan perbandingan antara pendapatan bunga bersih terhadap rata-rata aktiva produktif. Pendapatan bunga bersih diperoleh dari pendapatan bunga dikurangi beban bunga. Aktiva produktif yang diperhitungkan adalah aktiva produktif yang menghasilkan bunga (interest bearing assets) (Wicaksana, 2011). Semakin besar rasio ini maka meningkatnya pendapatan bunga atas aktiva produktif yang dikelola bank sehingga kemungkinan bank dalam kondisi bermasalah semakin kecil.

Biaya Operasional terhadap Pendapatan Operasional (BOPO) digunakan untuk mengukur tingkat efisiensi dan kemampuan bank dalam melakukan kegiatan operasinya (Kurniasari, 2013). Semakin kecil nilai BOPO maka semakin baik kinerja keuangan perbankan. Begitu juga sebaliknya, jika BOPO semakin besar maka akan semakin menurun kinerja keuangan perbankan.

Rasio LDR digunakan untuk mengukur kemampuan bank tersebut mampu membayar hutang-hutangnya dan membayar kembali, serta dapat memenuhi permintaan kredit yang diajukan. LDR adalah rasio antara seluruh jumlah kredit yang diberikan terhadap dana pihak ketiga. Besarnya jumlah kredit yang disalurkan akan menentukan keuntungan bank. Jika bank tidak mampu menyalurkan kredit sementara dana yang terhimpun banyak maka akan menyebabkan bank tersebut rugi (Kasmir, 2011).

\section{Profitabilitas (ROA)}

Profitabilitas merupakan ukuran kemampuan bank dalam meningkatkan labanya apakah setiap periode atau untuk mengukur tingkat efisiensi usaha dan profitabilitas yang dicapai bank yang bersangkutan (Kasmir, 2009:50-53). Return on Assets (ROA) digunakan untuk mengukur kemampuan manjemen bank dalam memperoleh keuntungan (laba) secara keseluruhan. Semakin besar ROA suatu bank, semakin besar pula tingkat keuntungan yang dicapai bank tersebut dan semakin baik pula posisi bank tersebut dari segi penggunaan aset (Kurniasari, 2013).

\section{Hipotesis}

Berdasarkan landasan teori di atas, maka diperoleh hipotesis sebagai berikut:

$\mathrm{H}_{1}$ : Diduga CAR, NPL, NIM, BOPO dan LDR berpengaruh secara parsial terhadap terhadap profitabilitas Bank Umum Swasta Nasional Devisa.

$\mathrm{H}_{2}$ : Diduga CAR, NPL, NIM, BOPO dan LDR berpengaruh secara simultan terhadap profitabilitas Bank Umum Swasta Nasional Devisa. 


\section{METODE PENELITIAN}

Populasi dalam penelitian ini adalah seluruh Bank Umum Swasta Nasional Devisa yang sudah go public dan mempublikasikan laporan keuangannya pada website resminya atau yang sudah melaporkan keuangannya pada Bank Indonesia dalam Direktori Perbankan. Untuk pengambilan sampel ini dilakukan dengan metode purposive sampling yaitu sampel dipilih berdasarkan kriteria tertentu. Kriteria yang dimaksud adalah: (1) Bank Umum Swasta Nasional Devisa yang mepublikasikan laporan keuangannya di Bursa Efek Indonesia (BEI) selama tahun 2013-2017. (2) Bank Umum Swasta Nasional Devisa yang konsisten melaporkan laporan keuangan setiap tahunnya dan mempublikasikannya dalam website BEI www.bi.go.id tahun 2013-2017. (3) Memiliki laporan keuangan yang lengkap (terutama item-item yang dapat dihitung dengan rasio keuangan).

Teknik analisis data yang digunakan dalam penelitian ini meliputi uji asumsi klasik, analisis regresi berganda, uji hipotesis. Uji asumsi klasik terdiri dari uji normalitas, uji multikolinearitas, uji heteroskedastisitas, dan uji auto korelasi. Sementara untuk uji hipotesis mengunakan uji statistic $t$, uji koefisien determinasi, dan uji F.

\section{TEMUANDAN PEMBAHASAN}

\section{Analisis Regresi Linear Berganda}

Analisis regresi linier berganda dalam penelitian ini, di hitung dengan menggunakan program IBM SPSS Statistics 20. Adapun hasil analisis dapat disajikan sebagai berikut :

\begin{tabular}{|c|c|c|c|c|}
\hline \multicolumn{5}{|c|}{ Tabel 1} \\
\hline \multirow{2}{*}{ Model } & \multicolumn{2}{|c|}{$\begin{array}{l}\text { Unstandardized } \\
\text { Coefficients }\end{array}$} & \multirow{2}{*}{$\mathrm{t}$} & \multirow{2}{*}{ Sig. } \\
\hline & B & $\begin{array}{l}\text { Std. } \\
\text { Error }\end{array}$ & & \\
\hline (Constant) & 4,869 & 2,662 & 1,829 & ,072 \\
\hline CAR & ,093 & ,042 & $-2,228$ & 030 \\
\hline NPL &,- 372 & 202 & $-1,836$ & ,072 \\
\hline NIM & 493 & 160 & 3,070 & ,003 \\
\hline BOPO & ,052 & ,019 & $-2,737$ & ,008 \\
\hline LDR & ,004 & ,019 & ,231 & ,818 \\
\hline
\end{tabular}

\section{Uji Hipotesis}

Uji t

Dari tabel 1 di atas, variabel CAR $\left(\mathrm{X}_{1}\right)$ menunjukkan bahwa signifikan $\mathrm{b}_{1}<5 \%(0,030<$ 0,05), maka dengan demikian pengujian menunjukkan Ho ditolak dan Ha diterima 
atau dengan kata lain variabel CAR $\left(\mathrm{X}_{1}\right)$ berpengaruh secara parsial terhadap profitabilitas (Y) Bank Umum Swasta Nasional Devisa.

Variabel NPL $\left(\mathrm{X}_{2}\right)$ menunjukkan bahwa signifikan $\mathrm{b}_{2}>5 \%(0,072>0,05)$, maka dengan demikian pengujian menunjukkan Ho diterima dan Ha ditolak atau dengan kata lain variabel NPL $\left(\mathrm{X}_{2}\right)$ tidak berpengaruh secara parsial terhadap profitabilitas $(\mathrm{Y})$ Bank Umum Swasta Nasional Devisa.

Variabel NIM $\left(X_{3}\right)$ menunjukkan bahwa signifikan $b_{3}<5 \%(0,003<0,05)$, maka dengan demikian pengujian menunjukkan Ho ditolak dan Ha diterima atau dengan kata lain variabel NIM $\left(\mathrm{X}_{3}\right)$ berpengaruh secara parsial terhadap profitabilitas (Y) Bank Umum Swasta Nasional Devisa.

Variabel BOPO $\left(\mathrm{X}_{4}\right)$ menunjukkan bahwa signifikan $\mathrm{b}_{4}<5 \%(0,008<0,05)$, maka dengan demikian pengujian menunjukkan Ho ditolak dan Ha diterima atau dengan kata lain variabel BOPO $\left(\mathrm{X}_{4}\right)$ berpengaruh secara parsial terhadap profitabilitas $(\mathrm{Y})$ Bank Umum Swasta Nasional Devisa.

Variabel LDR $\left(X_{5}\right)$ menunjukkan bahwa signifikan $b_{5}>5 \%(0,818>0,05)$, maka dengan demikian pengujian menunjukkan Ho diterima dan Ha ditolak atau dengan kata lain variabel LDR $\left(\mathrm{X}_{5}\right)$ tidak berpengaruh secara parsial terhadap profitabilitas $(\mathrm{Y})$ Bank Umum Swasta Nasional Devisa.

\section{Uji F}

Tabel 2

\begin{tabular}{lrrrr}
\hline Model & df & Mean Square & F & Sig. \\
\hline Regression & 5 & 24,495 & 11,199 &, $000^{\mathrm{b}}$ \\
Residual & 58 & 2,187 & & \\
Total & 63 & & & \\
\hline
\end{tabular}

Berdasarkan tabel 2 di atas dapat dilihat bahwa signifikansi $\mathrm{F}<5 \%(0,000<0,05)$. Dengan demikian Ho ditolak dan Ha diterima, yang berarti secara simultan variabel CAR $\left(X_{1}\right)$, NPL $\left(X_{2}\right)$, NIM $\left(X_{3}\right)$, BOPO $\left(X_{4}\right)$, LDR $\left(X_{5}\right)$ mempunyai pengaruh yang signifikan terhadap profitabilitas $(\mathrm{Y})$ Bank Umum Swasta Nasional Devisa.

\section{PEMBAHASAN}

\section{Pengaruh secara Parsial}

1. Pengaruh variabel CAR $\left(X_{1}\right)$ secara parsial terhadap profitabilitas $(Y)$ Variabel CAR $\left(X_{1}\right)$ menunjukkan bahwa signifikan $b_{1}<5 \%(0,030<0,05)$, maka dengan demikian pengujian menunjukkan Ho ditolak dan Ha diterima atau dengan kata lain variabel CAR $\left(X_{1}\right)$ berpengaruh secara parsial terhadap profitabilitas (Y) Bank Umum Swasta Nasional Devisa.

2. Pengaruh variabel NPL $\left(\mathrm{X}_{2}\right)$ secara parsial terhadap profitabilitas $(\mathrm{Y})$ 
Dari hasil penelitian variabel NPL $\left(\mathrm{X}_{2}\right)$ menunjukkan bahwa signifikan $\mathrm{b}_{2}>5 \%$ $(0,072>0,05)$, maka dengan demikian pengujian menunjukkan Ho diterima dan Ha ditolak atau dengan kata lain variabel NPL $\left(\mathrm{X}_{2}\right)$ tidak berpengaruh secara parsial terhadap profitabilitas (Y) Bank Umum Swasta Nasional Devisa.

3. Pengaruh variabel NIM $\left(\mathrm{X}_{3}\right)$ secara parsial terhadap profitabilitas $(\mathrm{Y})$

Berdasarkan uji $t$ yang telah dilakukan dapat diketahui bahwa signifikan $\mathrm{b}_{3}<5 \%$ $(0,003<0,05)$, maka dengan demikian pengujian menunjukkan Ho ditolak dan Ha diterima atau dengan kata lain variabel NIM $\left(X_{3}\right)$ berpengaruh secara parsial terhadap profitabilitas (Y) Bank Umum Swasta Nasional Devisa.

4. Pengaruh variabel BOPO $\left(\mathrm{X}_{4}\right)$ secara parsial terhadap profitabilitas $(\mathrm{Y})$

Dari uji $\mathrm{t}$ yang telah dilakukan dalam penelitian ini dapat diketahui bahwa $\mathrm{b}_{4}<$ $5 \%(0,008<0,05)$, maka dengan demikian pengujian menunjukkan Ho ditolak dan Ha diterima atau dengan kata lain variabel $\mathrm{BOPO}\left(\mathrm{X}_{4}\right)$ berpengaruh secara parsial terhadap profitabilitas (Y) Bank Umum Swasta Nasional Devisa.

5. Pengaruh variabel LDR $\left(\mathrm{X}_{5}\right)$ secara parsial terhadap profitabilitas $(\mathrm{Y})$

Uji parsial LDR $\left(X_{5}\right)$ menunjukkan bahwa signifikan $b_{5}>5 \%(0,818>0,05)$, maka dengan demikian pengujian menunjukkan Ho diterima dan Ha ditolak atau dengan kata lain variabel LDR $\left(\mathrm{X}_{5}\right)$ tidak berpengaruh secara parsial terhadap profitabilitas (Y) Bank Umum Swasta Nasional Devisa.

\section{Pengaruh secara Simultan}

Berdasarkan hasil uji $\mathrm{F}$ memperlihatkan bahwa semua variabel independent yaitu CAR $\left(X_{1}\right)$, NPL $\left(X_{2}\right)$, NIM $\left(X_{3}\right)$, BOPO $\left(X_{4}\right)$, LDR $\left(X_{5}\right)$ secara bersama-sama atau simultan mempengaruhi profitabilitas (Y) Bank Umum Swasta Nasional Devisa. Hal ini bisa dilihat dari signifikansi $\mathrm{F}<5 \%(0,000<0,05)$, maka dengan demikian pengujian menunjukkan Ho ditolak dan Ha diterima.

\section{KESIMPULAN DAN SARAN}

\section{Kesimpulan}

Berdasarkan hasil penelitian dan pembahasan, maka kesimpulan yang didapatkan penulis adalah sebagai berikut :

1. Berdasarkan uji t yang telah dilakukan dapat diketahui bahwa variabel CAR $\left(\mathrm{X}_{1}\right)$, NIM $\left(X_{3}\right)$ dan BOPO $\left(X_{4}\right)$ berpengaruh secara parsial terhadap profitabilitas $(Y)$ Bank Umum Swasta Nasional Devisa. Sedangkan variabel NPL $\left(\mathrm{X}_{2}\right)$ dan LDR ( $\left.\mathrm{X}_{5}\right)$ tidak berpengaruh secara parsial terhadap profitabilitas (Y) Bank Umum Swasta Nasional Devisa.

2. Berdasarkan hasil uji $F$ memperlihatkan bahwa semua variabel independen yaitu CAR $\left(X_{1}\right)$, NPL $\left(X_{2}\right)$, NIM $\left(X_{3}\right)$, BOPO $\left(X_{4}\right)$, dan LDR $\left(X_{5}\right)$ secara bersama-sama atau simultan mempengaruhi profitabilitas $(\mathrm{Y})$ Bank Umum Swasta Nasional Devisa. Hal ini bisa dilihat dari signifikansi $\mathrm{F}<5 \%(0,000<0,05)$. 


\section{Saran}

Berdasarkan hasil analisis data dan kesimpulan diatas, maka penulis menyampaikan saran sebagai berikut :

1. Sebaiknya dilakukan penelitian lebih lanjut mengenai faktor-faktor yang mempengaruhi profitabilitas yaitu dengan penambahan variabel independen.

2. Agar mendapatkan perbandingan hasil, peneliti selanjutnya diharapkan untuk menambah periode penelitian atau mengubah sampel yang digunakan.

\section{DAFTAR PUSTAKA}

Cecaria Mega Tiara, 2015., Analisis Faktor-Faktor yang Membentuk Kinerja (CAMELS) pada Perbankan Indonesia: (Studi Empiris pada Perbankan yang Terdaftar di BEI Periode 2009-2012), Skripsi, Fakultas Ekonomika dan Bisnis Universitas Diponegoro, Semarang

Kasmir. 2011. Manajemen Perbankan. Edisi Revisi . Jakarta:Rajawali Pers.

Kurniasari Christiana, 2013., Analisa Pengaruh Rasio CAMEL dalam Memprediksi Finacial Distress Perbankan Indonesia, Skripsi, Fakultas Ekonomika dan Bisnis Universitas Diponegoro, Semarang

Mismiwati. 2016. Pengaruh CAR, NIM, BOPO, LDR dan NPL terhadap ROA (Studi pada PT. BPD SUMSEL BABEL), I-Finance Vol. 2. No. 1. Juli 2016

Purwanto, dkk (2015). Analisis Pengaruh CAR, NIM, BOPO, dan LDR Terhadap Profitabilitas Bank Persero, Faculty of Business, President University, Bekasi, Indonesia

Raharjo, dkk (2014). Pengaruh rasio CAR, NPL, LDR, BOPO, dan NIM terhadap Kinerja Bank Umum di Indonesia, Jurnal Ekonomi Manajemen Sumber Daya Vol. 15, No. 2, Desember 2014

Taswan. 2010. Manajemen Perbankan. Edisi 2. Yogyakarta: UPP STIM YKPN.

Wicaksana Rizki Ludy, 2011., Analisis Pengaruh Rasio CAMEL terhadap Kondisi

Bermasalah pada Sektor Perbankan di Indonesia, Skripsi, Fakultas Ekonomi Universitas Diponegoro, Semarang

www.idx.co.id

www.bi.go.id 